\title{
Thai version of the foot function index: a cross-cultural adaptation with reliability and validity evaluation
}

\author{
Sunee Bovonsunthonchai ${ }^{1 *}$ (D), Suthasinee Thong-On ${ }^{1}$ (D), Roongtiwa Vachalathiti ${ }^{1}$, Warinda Intiravoranont ${ }^{2}$ (D), \\ Sarawut Suwannarat ${ }^{2}$ (B) and Richard Smith $^{3}$ (B)
}

\begin{abstract}
Background: The study aimed to translate the foot function index (FFI) questionnaire to Thai and to determine psychometric properties of the questionnaire among individuals with plantar foot complaints.

Methods: The Thai version of the FFI (FFI-Th) was adapted according to a forward and backward translation protocol by two independent translators and analyzed by a linguist and a committee. The FFI-Th was administered among 49 individuals with plantar foot complaints to determine internal consistency, reliability, and validity. Cronbach's alpha and the Intraclass Correlation Coefficient $\left(\mathrm{ICC}_{3,1}\right)$ were used to test the internal consistency and test-retest reliability. The Principal Component Analysis with varimax rotation method was used to test the factor structure and construct validity. Furthermore, the criterion validity was tested using Pearson's correlation coefficient $\left(r_{p}\right)$ between the FFI-Th and the visual analogue pain scale (pain-VAS) as well as the EuroQol five-dimensional questionnaire (EQ-5D-5L).
\end{abstract}

Results: The FFI-Th showed good to excellent internal consistency and test-retest reliability in the total score, pain, disability, and activity limitation subscales. The Principal Component Analysis produced 4 principal factors from the FFI-Th items. Criterion validity of the FFI-Th total score showed moderate to strong correlations with pain-VAS and EQ-5D-5L, and EQ-VAS scores.

Conclusion: The FFI-Th was a reliable and valid questionnaire to assess the foot function in a Thai population.

Trial registration: NCT03161314 (08/05/2017).

Keywords: Foot function index, Cross-cultural adaptation, Validity, Reliability

\section{Background}

Feet are an important structure used for transmitting forces to the ground when performing weight-bearing activities in daily life. While walking, structures and composites of the foot contribute the function as an absorber for the forces, an adaptor to uneven surfaces, and a facilitator to push the body forward. The occurrence of

\footnotetext{
* Correspondence: sunee.bov@mahidol.edu

${ }^{1}$ Faculty of Physical Therapy, Mahidol University, 999 Phuttamonthon 4 Rd., Salaya, Phuttamonthon, Nakhon Pathom 73170, Thailand

Full list of author information is available at the end of the article
}

foot pain disrupts biomechanical functions, leading to impaired mobility and balance, increased risk of fall and decreased independence [1-4]. Therefore, foot problems may eventually lead to injuries in other regions such as the knees, hips, pelvis and back.

Foot pain can occur among both sexes and across all age ranges $[4,5]$. It has been associated with the advancing of age, female sex, obesity, diabetes, falls, depression, disability and pain from other body parts $[1,5-10]$. It has been ranked 9th of the musculoskeletal problems after the low back, shoulders, neck, knees, wrist/shands,

C C The Author(s). 2020 Open Access This article is licensed under a Creative Commons Attribution 4.0 International License, which permits use, sharing, adaptation, distribution and reproduction in any medium or format, as long as you give appropriate credit to the original author(s) and the source, provide a link to the Creative Commons licence, and indicate if changes were made. The images or other third party material in this article are included in the article's Creative Commons licence, unless indicated otherwise in a credit line to the material. If material is not included in the article's Creative Commons licence and your intended use is not permitted by statutory regulation or exceeds the permitted use, you will need to obtain permission directly from the copyright holder. To view a copy of this licence, visit http://creativecommons.org/licenses/by/4.0/ The Creative Commons Public Domain Dedication waiver (http://creativecommons.org/publicdomain/zero/1.0/) applies to the data made available in this article, unless otherwise stated in a credit line to the data. 
higher back, hips and elbow regions [11]. When foot pain occurs, pain can limit overall function. Assessing foot symptoms requires a standardized instrument to provide reliable and valid findings. This will assist health professionals to obtain precise foot health status and to achieve proper results after treating correctly.

The Foot Function Index (FFI) has been developed and used as a self-reporting questionnaire covering several dimensions of foot function [12]. It contains 23 items, categorized in 3 subscales that quantify the impacts of foot problems on pain, disability and activity limitation. The FFI is one of the questionnaires widely used in the clinic and research of various pathologies of the foot and ankle [13-16]. It has been proved to have high reliability and validity as well as having been translated into several languages such as German [17], Taiwan Chinese [18], Chinese [19], Italian [16, 20, 21], Spanish [22], Brazilian Portuguese [23], Danish [24], Turkish [25], and Persian [26].

It has also been translated to Thai [27]; however, the scoring was adapted to use a numeric value instead of rating as a continuous scale which may affect its interpretation and the process of statistical analysis. There have been arguments about the psychometric property of different types of pain scale. Many studies demonstrated the same level with high reliability among the scales in the ICU cases [28], post-operative pain patients [29], and migraine patients [30], while one study showed that the numeric rating scale had higher reliability in illiterate patients [31]. In order to apply the FFI to evaluate even a small amount of change which may occur in a low or mild pain symptom, this study used a continuous scale as representing in the VAS.

In addition, information was lacking about grouping the items in the questionnaire. Thus, this study aimed to translate the English version of the FFI to Thai (FFI-Th) and to test its psychometric properties among individuals with plantar foot complaints. We hypothesized that the Thai version of FFI would have high reliability and validity, similar to the original and other language versions and could be used to test the foot function in Thai people validly and reliably.

\section{Methods}

\section{Study design}

A cross-sectional design was used in this study. Data were collected from May to December 2017.

\section{Cross-cultural translation}

The FFI questionnaire was translated to Thai version, following a cross-cultural adaptation recommended guideline [32]. The translation steps consisted of: 1) forward translation from the English version to a Thai version by two bilingual Thai and English translators independently; 2) reconciliation of the two forward versions of the FFI by an expert committee using synthesis into the FFI-Th to reduce discrepancies; 3) backward translation of the FFI-Th to English by two independent United States citizens who understood both Thai and English for checking the translated texts; 4) harmonization by developing the pre-final version of the FFI-Th through consensus of a group meeting of health professionals; 5) cognitive interview, by administering the pre-final version of the FFI-Th to 20 general individuals to check the understanding of the question items and 6) proofreading of the final version of the FFI-Th by a linguist. The final version of the FFI-Th was then launched in trials. A summary of the translation procedure is presented in Fig. 1.

Similar to the original version of the FFI, the FFI-Th contains 23 items, including 3 subscales, which are pain (items 1 st to 9th), disability (items 10th to 18th) and activity limitation (items 19th to 23rd). Each item is rated on a $10-\mathrm{cm}$ horizontal line visual analogue scale (VAS). The left and right ends of the line are labelled as "no pain" and "worst pain imaginable" for the pain item, "no difficulty" and "so difficult - unable" for the disability item, and "none of the time" and "all of the time" for the activity limitation item, respectively. Participants marked their levels of pain and discomfort at any point on the line that corresponded to their foot symptoms. The participant's response was measured by ruler on a continuous scale of $10 \mathrm{~cm}$ of the VAS line. Therefore, the maximum score for the 23 FFI-Th items was 230, with 90, 90 and 50 being the maximum scores for the pain, disability and activity limitation subscales respectively. A higher score represents a higher severity of pain, disability, and activity limitation [12]. Participants were asked to rate the score in all items of the FFI-Th. When they did not experience the situations of items, they were advised to check the "NA" (not applicable) box instead. The scoring system for the total score and sum of three subscales of FFI was converted to $0-100$ scores, by using the formula: sum of score from all items answered by participants, divided by the total score possible, and multiplied by 100 [12].

\section{Outcome measures}

The EuroQol five-dimensional questionnaire (EQ-5D-5L)

The EQ-5D-5L, a self-assessed, health-related, quality of life questionnaire, was developed by the EuroQol group to improve the sensitivity and reduce the ceiling effect of the previous (EQ-5D-3L) shortened version [33]. The EQ-5D-5L consists of the EQ-5D descriptive system and the EQ-VAS is available in over 130 languages including Thai. The five dimensions of the EQ-5D descriptive system are 1) mobility, 2) self-care, 3) usual activities, 4) pain/discomfort and 5) anxiety/depression. Each 


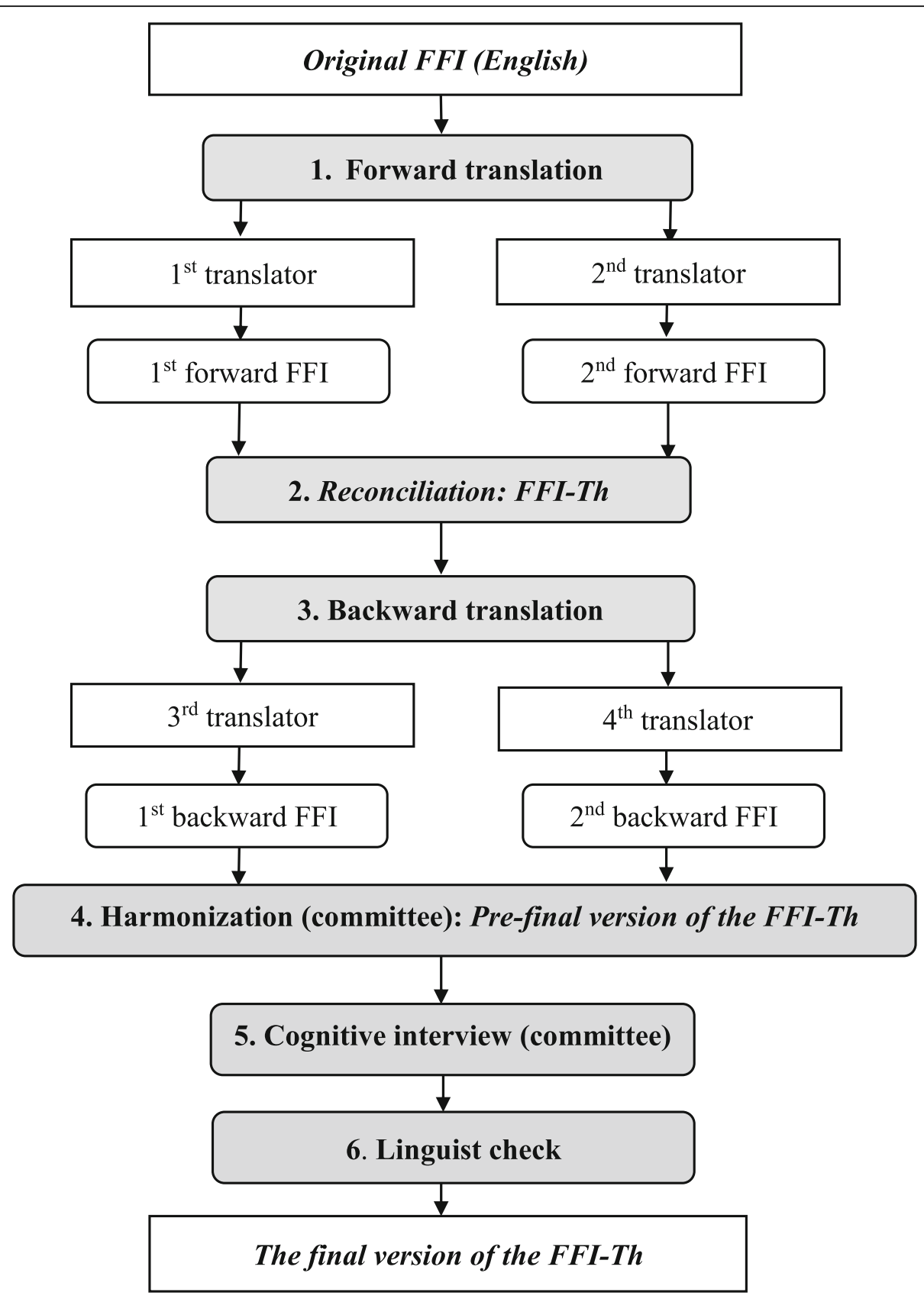

Fig. 1 Flowchart of the translation procedure

dimension has 5 levels of the score comprising no, slight, moderate, severe and extreme problems. Participants were asked to indicate their health status by checking in the box presenting the most appropriate description. Decision results from 5 dimensions can be interpreted in a 5 -digit number describing the respondent's health status. The questionnaire could be used as a health index with utility value or as a health descriptive profile. The calculation process of the EQ-5D utility value in this study was obtained from a previous study [34]. The EQ-VAS records the self-rated health on the vertical VAS line, where the endpoints labelled as "the best health you can imagine" and "the worst health you can imagine".

The VAS of pain (pain-VAS)

The pain-VAS, a uni-dimensional measure of pain intensity is used in diverse populations and settings due to its simplicity and adaptability. The pain-VAS is a continuous scale, usually $10 \mathrm{~cm}$ anchoring with two different verbal descriptions at each end of the line [35, 36]. Instructions and verbal descriptions may differ, depending on the intended use. As a self-assessment report 
respondents required no training. Respondents can rate their symptoms by marking on the line [35, 37]. A higher score indicates greater pain intensity. Test-retest reliability of the pain-VAS has been proved to be high [38] and construct validity with a numeric rating scale was good to excellent [39].

\section{Sample size calculation}

Sample size was calculated from the study of Jorgensen et al. in 2015 [24] who tested reliability of the FFIDenmark version (FFI-DK). Excellent test-retest reliability of the FFI-DK was reported for each subscale [pain (ICC $=0.98$ and $95 \% \mathrm{CI}=0.97-0.99)$, activity limitation (ICC $=0.95$ and $95 \% \mathrm{CI}=0.91-0.98$ ), and disability ( $\mathrm{ICC}=0.97$ and $95 \% \mathrm{CI}=0.95-0.98)]$ and the total score of FFI-DK (ICC $=0.95$ and $95 \%$ CI $=0.91-0.98$ ). Sample size was calculated from the formula shown below.

$$
m_{\text {repeat }}=\frac{2 \xi(1-\xi)\left(1-2 \xi+2 \xi^{2}\right) \mathrm{z}^{2}{ }_{1-\alpha / 2}}{\mathrm{w} \xi^{2}(1-2 \xi)^{2}}
$$

Where $\mathrm{m}_{\text {repeat }}$ was the number of samples, $\mathrm{z}_{1-\alpha / 2}^{2}$ was set at 1.96. The $\xi$ was a chance error and WE was the desired width, which was set at 0.10 and 0.15 respectively. Based on this calculation, the sample size was 48 . Thus, the number of participants recruited in the study satisfies this requirement.

\section{Statistical analyses}

SPSS version 20 (IBM corp, USA) was used to analyze the data with a significance level set at $p<0.05$. Descriptive analysis was used to present the demographic data and subscales of the FFI-Th. The floor effect (0 score), ceiling effect (10 scores) and not applicable (NA) answers were counted.

Cronbach's alpha (CA) was used to test the internal consistency of the FFI-Th. The CA values ranged from 0 (no internal consistency) to the full score of 1 (perfect internal consistency). Test-retest reliability of the FFI-Th was evaluated between the first and the second administrations with 1 week apart by the $\mathrm{ICC}_{3,1}$ and $95 \%$ confidence interval $(95 \% \mathrm{CI})$. The ICC values ranged from 0 (no agreement) to the full score of 1 (perfect agreement). The ICC $<0.5$ was considered as poor, 0.5 to 075 was moderate, 0.75 to 0.9 was good, and $>0.9$ was excellent reliability [40]. Construct validity of the FFI-Th was tested using Principal Component Analysis with the varimax rotation method and considering the eigenvalue was greater than 1 . Criterion validity of the pain-VAS and the EQ-5D-5L were investigated using Pearson's correlation coefficient $(r)$, with the possible range of coefficient was 0 to 1 . Interpretations of these coefficients were $\mathrm{r}<0.3$ (weak correlation), 0.3 to 0.5 (moderate correlation), and $>0.5$ (strong correlation) [41]. The positive and negative values indicated the positive and negative directions of correlation.

\section{Participants}

Before conducting this study, participants were informed about the details of the study and signed informed consent forms approved by the institutional ethics committee (MU-CIRB COA no. 2016/ 173.3012). Inclusion criteria of the participants were: 1) aged between 20 and 80 years; 2) had pain or tenderness at the plantar surface of the foot during rest and/or during prolonged weight-bearing activities of at least 1 month; 3 ) able to read and communicate in the Thai language and 4) had no visual problems that could not be corrected by lens or glasses. They were excluded if they had: 1) pain in any other areas of the lower extremity; 2) history of systematic inflammatory disease or neurological disease and 3) received any kind of treatment during participation in the study. There were 51 individuals with plantar foot complaints who passed the selection criteria. Of these, 2 participants did not rate the score for the EQ-5D$5 \mathrm{~L}$ questionnaire. Therefore, 49 participants were included in this study. Demographic data and clinical symptoms of foot pain are presented in Table 1.

Table 1 Demographic data and clinical symptoms of the participants $(n=49)$

\begin{tabular}{lcl}
\hline Variables & Mean \pm SD or number (\%) & Range \\
\hline Sex (number (\%)) & $10(20.41 \%)$ & - \\
Male & $39(79.59 \%)$ & - \\
Female & $47.22 \pm 14.35$ & $20-78$ \\
Age (years) & $65.69 \pm 17.93$ & $44-136$ \\
Weight (kg) & $160.73 \pm 8.09$ & $147-179$ \\
Height (cm) & $2(4.08 \%)$ & - \\
Leg dominant side (number (\%)) & - \\
Left & $47(95.92 \%)$ & - \\
Right & & - \\
Pain side (number (\%)) & $16(32.65 \%)$ & - \\
Left & $16(32.65 \%)$ & - \\
Right & $17(34.70 \%)$ & -36 \\
Both & & \\
Pain behaviour & $38(77.51 \%)$ & - \\
Intermittent & $11(22.45 \%)$ & \\
Constant & $7.95 \pm 11.01$ & \\
Onset duration, months & & - \\
\hline
\end{tabular}




\section{Results}

\section{Distribution of the score for the FFI-Th}

The FFI-Th score was calculated from the score marked on a $10 \mathrm{~cm}$ horizontal line for each item. At the end of each question, there was the "NA" box using for the ones to rate if the question was not consistent with their previous experience leading to inability to rate the score. Missing values were excluded and the data were computed using the scoring system following recommendation [12] and method used in previous studies [18, 20, 22]. Following these guidelines, the totals and subscale sum scores were all reported in the range of 0 to 100 . Table 2 presents the mean and SD of the FFI-Th scores from the completed analysis and the numbers and percentages of respondents who reported floor score, ceiling score, and NA answer. With the scoring system, an averaged total score of FFI-Th of the participants was $27.60 \pm$ 20.30. Averaged subscales of pain, disability and activity limitation were $33.42 \pm 21.60,31.17 \pm 23.57$, and $14.34 \pm 15.19$, respectively. One to three participants reported floor scores for the items in the pain and disability subscales, whereas 7 to 16 participants reported floor scores for the items in the activity limitation subscale. For ceiling score, only one participant reported it in the 1st and 2nd items. For N/A score,

Table 2 Mean and standard deviation, number and percentage of the completer, floor, ceiling scores, and not applicable (NA) answers of the $\mathrm{FFI}-\mathrm{Th}$

\begin{tabular}{|c|c|c|c|c|}
\hline Item & $\begin{array}{l}\text { Completer score }^{a} \\
\text { (mean } \pm \text { SD) }\end{array}$ & $\begin{array}{l}\text { Floor score } \\
\text { n (\%) }\end{array}$ & $\begin{array}{l}\text { Ceiling score } \\
\text { n (\%) }\end{array}$ & $\begin{array}{l}\text { Not applicable (NA) } \\
\text { n (\%) }\end{array}$ \\
\hline Total score (0-100 scores) & $27.60 \pm 20.30$ & - & - & - \\
\hline Pain subscale (0-100 scores) & $33.42 \pm 21.60$ & - & - & - \\
\hline \multicolumn{5}{|l|}{ Sub-items 1-9 (0-10 scores) } \\
\hline 1. Worst foot pain & $4.07 \pm 2.71$ & $0(0)$ & $1(2.04)$ & $0(0)$ \\
\hline 2. Morning foot pain & $3.74 \pm 2.69$ & $2(4.08)$ & $1(2.04)$ & $0(0)$ \\
\hline 3. Pain walking barefoot & $3.82 \pm 2.67$ & $2(4.08)$ & $0(0)$ & $0(0)$ \\
\hline 4. Pain standing barefoot & $3.14 \pm 2.45$ & $3(6.12)$ & $0(0)$ & $0(0)$ \\
\hline 5. Pain walking with shoes & $2.99 \pm 2.16$ & $1(2.04)$ & $0(0)$ & $0(0)$ \\
\hline 6. Pain standing with shoes & $2.79 \pm 2.20$ & $3(6.12)$ & $0(0)$ & $1(2.04)$ \\
\hline 7. Pain walking with orthotics & $2.15 \pm 2.03$ & $3(6.12)$ & $0(0)$ & $26(53.06)$ \\
\hline 8. Pain standing with orthotics & $2.13 \pm 2.00$ & $3(6.12)$ & $0(0)$ & $26(53.06)$ \\
\hline 9. Foot pain at end of day & $3.76 \pm 2.60$ & $1(2.04)$ & $0(0)$ & $4(8.16)$ \\
\hline Disability subscale (0-100 scores) & $31.17 \pm 23.57$ & - & - & - \\
\hline \multicolumn{5}{|l|}{ Sub-items 10-18 (0-10 scores) } \\
\hline 10. Walking in house & $2.42 \pm 2.28$ & $5(10.20)$ & $0(0)$ & $0(0)$ \\
\hline 11. Walking outside & $3.51 \pm 2.78$ & $3(6.12)$ & $0(0)$ & $0(0)$ \\
\hline 12. Walking four blocks & $3.53 \pm 2.51$ & $3(6.12)$ & $0(0)$ & $3(6.12)$ \\
\hline 13. Climbing stairs & $2.80 \pm 2.40$ & $5(10.20)$ & $0(0)$ & $1(2.04)$ \\
\hline 14. Descending stairs & $3.07 \pm 2.49$ & $4(8.16)$ & $0(0)$ & $1(2.04)$ \\
\hline 15. Standing on tiptoes & $2.92 \pm 2.43$ & $3(6.12)$ & $0(0)$ & $1(2.04)$ \\
\hline 16. Getting up from chair & $2.90 \pm 2.70$ & $6(12.24)$ & $0(0)$ & $0(0)$ \\
\hline 17. Climbing curbs & $2.95 \pm 2.47$ & $4(8.16)$ & $0(0)$ & $1(2.04)$ \\
\hline 18. Running or walking fast & $4.09 \pm 2.82$ & $1(2.04)$ & $0(0)$ & $3(6.12)$ \\
\hline Activity limitation subscale (0-100 scores) & $14.34 \pm 15.19$ & - & - & - \\
\hline \multicolumn{5}{|l|}{ Sub-items19-23 (0-10 scores) } \\
\hline 19. Using device indoors & $1.81 \pm 2.17$ & $13(26.53)$ & $0(0)$ & $2(4.08)$ \\
\hline 20. Using device outdoors & $1.05 \pm 1.43$ & $14(28.57)$ & $0(0)$ & $5(10.20)$ \\
\hline 21. Staying inside all day & $2.19 \pm 2.38$ & $7(14.29)$ & $0(0)$ & $3(6.12)$ \\
\hline 22. Staying in bed all day & $0.63 \pm 1.19$ & $16(32.65)$ & $0(0)$ & 19 (38.78) \\
\hline 23. Limiting activities & $0.49 \pm 0.85$ & $16(32.65)$ & $0(0)$ & 19 (38.78) \\
\hline
\end{tabular}

${ }^{a}$ Completer score, the N/A answers were excluded in the analysis 
Table 3 Internal consistency (CA) and test-retest reliability $\left(I C C_{3}\right.$, 1) of the FFI-Th

\begin{tabular}{lllll}
\hline Item & CA & $\mathbf{I C C}_{3,1}$ & $\mathbf{9 5 \%} \mathbf{C l}$ & $\boldsymbol{p}$-value \\
\hline Total & 0.974 & 0.942 & $0.897-0.967$ & $<0.001$ \\
Pain & 0.946 & 0.904 & $0.830-0.946$ & $<0.001$ \\
1. Worst foot pain & 0.891 & $0.808-0.939$ & $<0.001$ \\
2. Morning foot pain & 0.899 & $0.821-0.943$ & $<0.001$ \\
3. Pain walking barefoot & 0.896 & $0.815-0.941$ & $<0.001$ \\
4. Pain standing barefoot & 0.829 & $0.696-0.903$ & $<0.001$ \\
5. Pain walking with shoes & 0.796 & $0.638-0.885$ & $<0.001$ \\
6. Pain standing with shoes & 0.692 & $0.451-0.827$ & $<0.001$ \\
7. Pain walking with orthotics & 0.918 & $0.807-0.965$ & $<0.001$ \\
8. Pain standing with orthotics & 0.902 & $0.765-0.959$ & $<0.001$ \\
9. Foot pain at end of day & 0.900 & $0.819-0.945$ & $<0.001$ \\
Disability & 0.975 & 0.938 & $0.890-0.965$ & $<0.001$ \\
10. Walking in house & & 0.921 & $0.860-0.955$ & $<0.001$ \\
11. Walking outside & 0.957 & $0.923-0.976$ & $<0.001$ \\
12. Walking four blocks & 0.830 & $0.693-0.906$ & $<0.001$ \\
13. Climbing stairs & 0.861 & $0.751-0.922$ & $<0.001$ \\
14. Descending stairs & 0.912 & $0.844-0.951$ & $<0.001$ \\
15. Standing on tiptoe & 0.876 & $0.773-0.932$ & $<0.001$ \\
16. Getting up from chair & 0.904 & $0.830-0.946$ & $<0.001$ \\
17. Climbing curbs & 0.908 & $0.833-0.949$ & $<0.001$ \\
18. Running or walking fast & 0.882 & $0.786-0.935$ & $<0.001$ \\
Activity limitation & 0.866 & $0.763-0.925$ & $<0.001$ \\
19. Using device indoors & 0.890 & $0.801-0.939$ & $<0.001$ \\
20. Using device outdoors & 0.795 & $0.621-0.889$ & $<0.001$ \\
21. Staying inside all day & 0.838 & $0.705-0.911$ & $<0.001$ \\
22. Staying in bed all day & 0.691 & $0.351-0.853$ & 0.001 \\
23. Limiting activities & 0.534 & $0.008-0.781$ & 0.024 \\
\hline The dat treated by the cold & & & &
\end{tabular}

The data treated by the cold deck technique

CA Cronbach's alpha, $I C C_{3,}$ Intraclass Correlation Coefficient of the two-way mixed model (Consistency), $\mathrm{Cl}$ Confidence interval

there were 26 participants could not rate the score for the 7th and 8th items and 19 for the 22nd and 23rd items.

\section{Internal consistency and test-retest reliability of the FFI- Th}

As presented in Table 3, good to excellent internal consistencies were found for the total score $(C A=0.974)$, subscales of pain $(\mathrm{CA}=0.946)$, disability $(\mathrm{CA}=0.975)$, and activity limitation $(\mathrm{CA}=0.714)$. Between two trials of testing, good to excellent test-retest reliabilities were found for the total score $\left(\mathrm{ICC}_{3,1}=0.942, p<0.001\right)$, subscales of pain $\left(\mathrm{ICC}_{3}, \quad 1=0.904, p<0.001\right)$, disability $\left(\mathrm{ICC}_{3,1}=0.938, p<0.001\right)$, and activity limitation $\left(\mathrm{ICC}_{3}\right.$, $\left.{ }_{1}=0.866, p<0.001\right)$.

\section{Construct validity}

The correlation matrix showed that the extraction was appropriate. This was observed using the Kaiser-MeyerOlkin and Bartlett's sphericity tests (the Kaiser-MeyerOlkin Measure $=0.856, p<0.001$ and the Chi-square value $=402.978$ ). The computation was performed after missing values were replaced by the mean values. Figure 2 shows the scree plot of all items of the FFI-Th. Fourfactor numbers showed eigenvalues greater than 1 .

Table 4 shows the total variance explained by factors which were extracted by the Principal Component Analysis using the varimax rotation method. For the extraction sums of squared loadings column, the first factor accounted for $60.393 \%$ of the variance, when the second, third and fourth merely accounted for 9.320, 6.623, and $5.220 \%$, respectively. For the rotation sums of squared loadings column, the first factor accounted for $50.527 \%$ of the variance, when the second, third, and fourth merely accounted for $11.346,9.867$, and $9.816 \%$, respectively.

Table 5 shows the loading of the four factors after performing exploratory factor analysis. The bold numbers (more than 0.6) show the high level of relationship of the questionnaire items to a single extracted factor. With the first factor, item load ranged from 0.370 (item 23rd) to 0.936 (item 11th). Items load ranged from -0.244 (item 1st) to 0.827 (item 22nd) for the second factor, 0.388 (item 8th) to 0.658 (item 20th) for the third factor, and -0.412 (item 23rd) to 0.550 (item 7 th) for the fourth factor.

\section{Criterion validity of the FFI-Th with the pain-VAS, EQ-5D- $5 \mathrm{~L}$, and EQ-VAS}

As presented in Table 6, strong correlations were found between the total score of the FFI-Th with the pain-VAS $\left(\mathrm{r}_{\mathrm{p}}=0.695, p<0.001\right)$, EQ-5D-5L $\left(\mathrm{r}_{\mathrm{p}}=-0.712, p<0.001\right)$, and EQ-VAS $\left(\mathrm{r}_{\mathrm{p}}=-0.508, p<0.001\right)$. The pain subscale of FFI-Th showed strong correlations with the pain-VAS $\left(\mathrm{r}_{\mathrm{p}}=0.755, p<0.001\right)$, EQ-5D-5L $\left(\mathrm{r}_{\mathrm{p}}=-0.626, p<0.001\right)$, and EQ-VAS $\left(\mathrm{r}_{\mathrm{p}}=-0.460, p=0.001\right)$. The disability subscale of FFI-Th showed strong correlations with the pain-VAS $\left(\mathrm{r}_{\mathrm{p}}=0.640, p<0.001\right)$, EQ-5D-5L $\left(\mathrm{r}_{\mathrm{p}}=-0.660\right.$, $p<0.001)$, and EQ-VAS $\left(\mathrm{r}_{\mathrm{p}}=-0.552, p<0.001\right)$. The activity limitation subscale showed strong correlation with the EQ-5D-5L $\left(r_{p}=-0.760, p<0.001\right)$ but showed weak and moderate correlations with the EQ-VAS $\left(r_{p}=-\right.$ 0.292, $p=0.042)$ and pain-VAS $\left(\mathrm{r}_{\mathrm{p}}=0.364, p=0.010\right)$.

\section{Discussion}

The FFI-Th presented good to excellent for internal consistency and test-retest reliability in the total score, pain subscale, disability subscale, and activity limitation subscale. The Principal Component Analysis of FFI-Th items showed 4 principal factors. Criterion validity of 


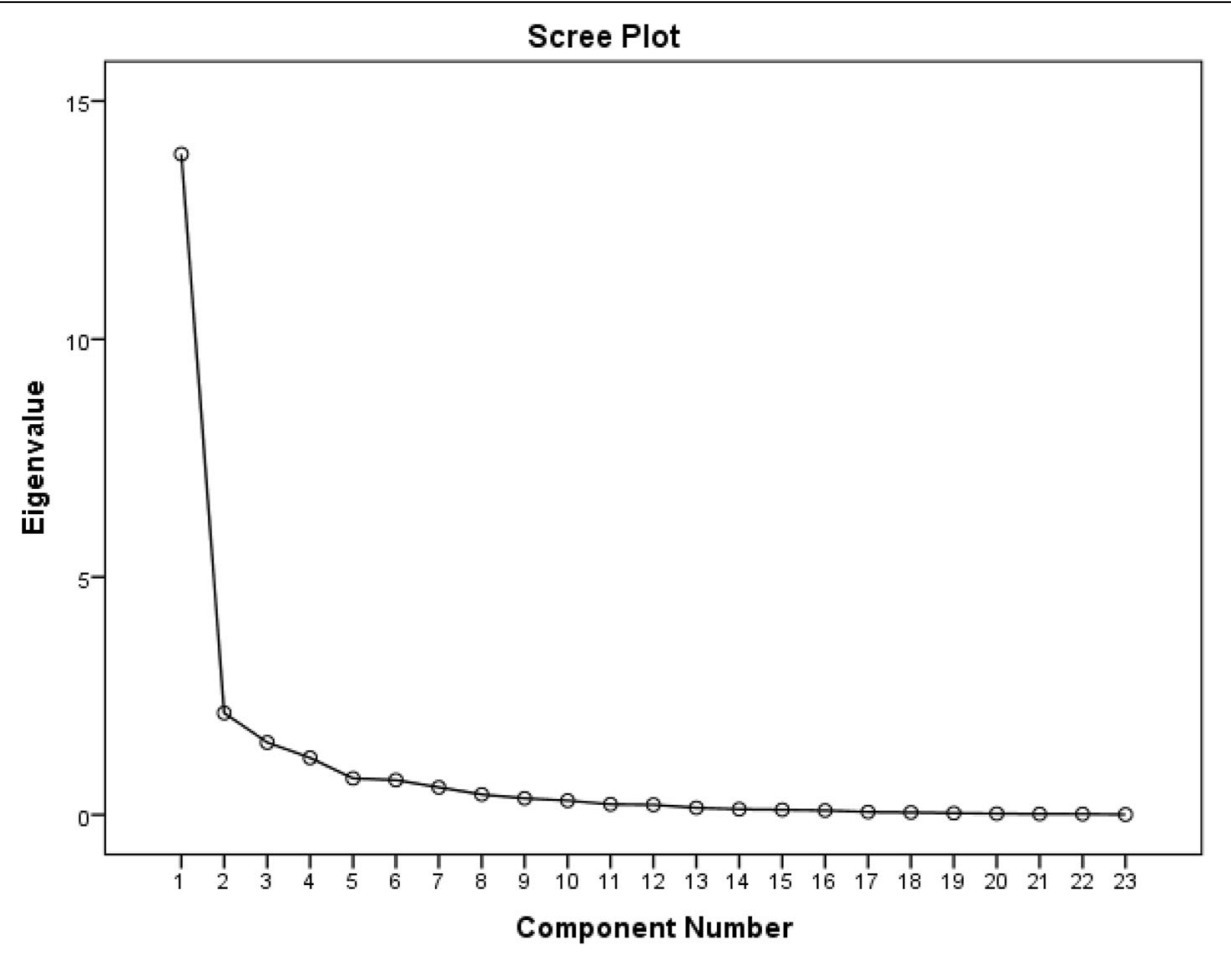

Fig. 2 Scree plot of the exploratory factor analysis

the FFI-Th presented moderate to strong correlations with pain-VAS and EQ-5D-5L, and EQ-VAS scores.

\section{Data distribution of the FFI-Th}

The participants in the present study all had plantar foot complaints, an average age of $47.22 \pm 14.35$ years, ranging from 20 to 78 years. Everyone was able to read and answer the questionnaire. Their mean and standard deviation of the total FFI-Th score $(27.60 \pm 20.30)$ agreed well with the average total FFI score determined in Rheumatoid Arthritis from a previous result (FFI total score of $28.09 \pm 23.26$ ) [12].

For the items of FFI-Th that were tested from this study, firstly, high ratios of NA answers were found in items 7th and 8th ( $n=26$ for each item), followed by the items 22 nd and 23rd ( $n=19$ for each item). Secondly, one participant reported ceiling scores in the pain subscale. Thirdly, a relatively low internal consistency was found in the activity limitation subscale when compared with the other subscales. In addition, we encountered difficulty in the translation of some items of the original FFI including the distance of a block, which was uncertain in Thailand and unrecognized by Thais. Moreover, $500 \mathrm{~m}$ or around 1 bus stop distance was substituted for the distance of roughly four blocks. For this aspect, the differences in culture and livelihood between locations should be researched more.
For the NA answering, this problem had also been reported in earlier studies [42, 43]. Agel et al. found $20 \%$ or more of NA answers in four items of the pain and activity limitation subscales [42]. In contrast to the study of Venditto et al., 92\% of NA answers were reported in six items of the pain subscale (3rd, 4th, 5th, 6th, 7th and 8th) [21]. According to the irrelevant items, this may make researcher modified the questionnaire as the shortened version [14, 17, 22, 43]. Among the questionnaire items, individuals who had less severity were unable to answer the questions of items 7th and 8th because they had no experiences of using orthotics or devices [14, 42, 43]. However, eliminating these items may have reduced the item numbers and may have affected the psychometric properties. Thus, it remains advisable to use the full 23item questionnaire to determine all points of consideration of foot function [18].

The validity and reliability of the questionnaire may be jeopardized when high floor or ceiling effects are present. Discrimination between subjects is decreased on an item where there are many answering with the lowest or highest possible scores [44]. In this study, floor and ceiling effects were determined by counting the number of individuals who obtained the lowest (0) or the highest (10) scores.

From our findings, floor scores were observed in almost all items, except for the 1st item (worst foot pain). 
Table 4 Total variance explained by the factors (extraction method: the principal component analysis with the varimax rotation)

\begin{tabular}{|c|c|c|c|c|c|c|c|c|c|}
\hline \multirow[t]{2}{*}{ Factor } & \multicolumn{3}{|c|}{ Initial Eigenvalues } & \multicolumn{3}{|c|}{ Extraction Sums of Squared Loadings } & \multicolumn{3}{|c|}{ Rotation Sums of Squared Loadings } \\
\hline & Total & $\%$ Variance & $\%$ Cumulative & Total & $\%$ Variance & $\%$ Cumulative & Total & $\%$ Variance & $\%$ Cumulative \\
\hline 1 & 13.890 & 60.393 & 60.393 & 13.890 & 60.393 & 60.393 & 11.621 & 50.527 & 50.527 \\
\hline 2 & 2.144 & 9.320 & 69.712 & 2.144 & 9.320 & 69.712 & 2.610 & 11.346 & 61.872 \\
\hline 3 & 1.523 & 6.623 & 76.336 & 1.523 & 6.623 & 76.336 & 2.269 & 9.867 & 71.739 \\
\hline 4 & 1.201 & 5.220 & 81.556 & 1.201 & 5.220 & 81.556 & 2.258 & 9.816 & 81.556 \\
\hline 5 & 0.766 & 3.332 & 84.887 & & & & & & \\
\hline 6 & 0.731 & 3.178 & 88.065 & & & & & & \\
\hline 7 & 0.577 & 2.510 & 90.575 & & & & & & \\
\hline 8 & 0.428 & 1.860 & 92.435 & & & & & & \\
\hline 9 & 0.346 & 1.506 & 93.942 & & & & & & \\
\hline 10 & 0.297 & 1.292 & 95.233 & & & & & & \\
\hline 11 & 0.221 & 0.961 & 96.194 & & & & & & \\
\hline 12 & 0.210 & 0.911 & 97.106 & & & & & & \\
\hline 13 & 0.146 & 0.637 & 97.742 & & & & & & \\
\hline 14 & 0.118 & 0.511 & 98.254 & & & & & & \\
\hline 15 & 0.106 & 0.460 & 98.714 & & & & & & \\
\hline 16 & 0.089 & 0.386 & 99.100 & & & & & & \\
\hline 17 & 0.060 & 0.262 & 99.362 & & & & & & \\
\hline 18 & 0.050 & 0.217 & 99.579 & & & & & & \\
\hline 19 & 0.034 & 0.150 & 99.729 & & & & & & \\
\hline 20 & 0.024 & 0.106 & 99.835 & & & & & & \\
\hline 21 & 0.017 & 0.075 & 99.910 & & & & & & \\
\hline 22 & 0.015 & 0.066 & 99.976 & & & & & & \\
\hline 23 & 0.006 & 0.024 & 100.000 & & & & & & \\
\hline
\end{tabular}

The highest number of respondents gave floor scores in the activity limitation sub-set, especially in items 22nd and $23 \mathrm{rd}$ ( $n=16$ or $32.65 \%$ for both items). It is possible that most of the participants were still carrying out their routine activities and could walk independently without using devices. According to the inclusion criteria, participants who had pain at the plantar surface of the foot during rest or weight-bearing activities were selected. Among those participants, most reported pain at the bottom part similar to the clinical symptoms in plantar fasciitis. Observing floor scores for the disability and activity limitation subscale in this study is consistent with the previous findings in studies that included plantar fasciitis cases [18].

\section{Internal consistency and test-retest reliability}

The FFI-Th demonstrated excellent internal consistency for the total score and subscales of pain and disability and provided CA values similar to the previous translation reports $[17,18,22]$. However, a relatively low internal inconsistency in the activity limitation subscale was observed in this study similar to the related studies $[14,18,42]$. This led one study to omit this subscale from the questionnaire [43], but it may reduce the comprehensive nature of overall domains.

For the test-retest reliability, the total score and sum scores of the pain and disability subscales showed excellent reliability, while the activity limitation subscale showed good reliability. This finding was similar to the previous results that showed somewhat lower reliability of the activity limitation than the other subscales [16]. When considering each item, the lowest reliability $\left(\mathrm{ICC}_{3}\right.$, ${ }_{1}=0.534$ ) was found in the item 23rd (Limiting activities). This may be the result of uncertainty in rating this item and the majority of participants had no problem of activity limitation.

\section{The construct validity and criterion validity}

In the original version, the three subscales included pain (evaluated by the items 1st - 9th), disability (assessed by the items 10th - 18th), and activity limitation (assessed with the items 19th - 23rd) [12]. However, when observing factor extraction performed through the Principal Component Analysis with the varimax rotation method, except for the items 7th and 8th, almost all items of the pain and disability subscales showed values more than 
Table 5 Factor loading distribution (extraction method: principal component analysis with varimax rotation)

\begin{tabular}{|c|c|c|c|c|c|}
\hline & \multirow[t]{2}{*}{ Items } & \multicolumn{4}{|c|}{ Factor loading $^{a}$} \\
\hline & & 1 & 2 & 3 & 4 \\
\hline \multirow[t]{9}{*}{ Pain } & 1. Worst foot pain & 0.779 & -0.244 & -0.181 & -0.022 \\
\hline & 2. Morning foot pain & 0.790 & -0.146 & 0.006 & 0.103 \\
\hline & 3. Pain walking barefoot & 0.909 & -0.133 & 0.075 & -0.074 \\
\hline & 4. Pain standing barefoot & 0.894 & -0.119 & 0.107 & -0.006 \\
\hline & 5. Pain walking with shoes & 0.868 & -0.033 & 0.008 & 0.050 \\
\hline & 6. Pain standing with shoes & 0.857 & -0.042 & 0.057 & 0.015 \\
\hline & 7. Pain walking with orthotics & 0.547 & 0.485 & -0.384 & 0.550 \\
\hline & 8. Pain standing with orthotics & 0.577 & 0.495 & -0.388 & 0.508 \\
\hline & 9. Foot pain at end of day & 0.765 & -0.049 & -0.246 & 0.001 \\
\hline \multirow[t]{9}{*}{ Disability } & 10. Walking in house & 0.915 & 0.080 & 0.066 & -0.108 \\
\hline & 11. Walking outside & 0.936 & -0.095 & 0.023 & -0.156 \\
\hline & 12. Walking four blocks & 0.870 & -0.104 & -0.152 & -0.203 \\
\hline & 13. Climbing stairs & 0.840 & -0.150 & -0.108 & -0.102 \\
\hline & 14. Descending stairs & 0.900 & -0.107 & -0.028 & 0.017 \\
\hline & 15. Standing on tiptoe & 0.860 & -0.007 & -0.081 & -0.176 \\
\hline & 16. Getting up from chair & 0.909 & -0.128 & 0.028 & -0.060 \\
\hline & 17. Climbing curbs & 0.913 & -0.087 & -0.112 & -0.035 \\
\hline & 18. Running or walking fast & 0.901 & -0.083 & -0.109 & 0.029 \\
\hline \multirow[t]{5}{*}{ Activity limitation } & 19. Using device indoors & 0.513 & -0.048 & 0.642 & 0.311 \\
\hline & 20. Using device outdoors & 0.442 & 0.322 & 0.658 & 0.291 \\
\hline & 21. Staying inside all day & 0.631 & -0.060 & 0.422 & 0.098 \\
\hline & 22. Staying in bed all day & 0.372 & 0.827 & 0.056 & -0.369 \\
\hline & 23. Limiting activities & 0.370 & 0.812 & 0.114 & -0.412 \\
\hline
\end{tabular}

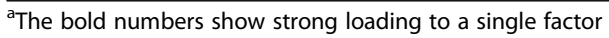

0.6 in the first factor, whereas only two different items load in the second and third factors. Factor analysis of the FFI-Th showed results similar to the previous article [22]. Exploratory factor analysis showed little relationship between the activity limitation subscale and the other two subscales, but a stronger relationship between the pain and disability subscales was found as shown in the first factor. Therefore, diminishing the activity

Table 6 Correlations $\left(r_{p}\right)$ of the FFI-Th with pain-VAS, EQ-5D-5L, and EQ-VAS

\begin{tabular}{llll}
\hline Variables & Pain-VAS & EQ-5D-5L & EQ-VAS \\
\hline FFI-Th: Total & $0.695^{*}$ & $-0.712^{*}$ & $-0.508^{*}$ \\
$p$-value & $<0.001$ & $<0.001$ & $<0.001$ \\
FFI-Th: Pain subscale & $0.755^{*}$ & $-0.626^{*}$ & $-0.460^{*}$ \\
$p$-value & $<0.001$ & $<0.001$ & 0.001 \\
FFI-Th: Disability subscale & $0.640^{*}$ & $-0.660^{*}$ & $-0.552^{*}$ \\
$p$-value & $<0.001$ & $<0.001$ & $<0.001$ \\
FFI-Th: Activity limitation subscale & $0.364^{*}$ & $-0.760^{*}$ & $-0.292^{*}$ \\
$p$-value & 0.010 & $<0.001$ & 0.042 \\
\hline${ }^{*}$ Significant tested by the Pearson correlation coefficient $\left(r_{\mathrm{p}}\right)$ at $p<0.05$
\end{tabular}

limitation subscale and items 7th and 8th (pain related to orthotic use when walking and standing) for further study in case of similar populations in the study may be recommended.

For criterion validity, many studies focused on the correlation between the FFI and different testing variables. In this study, we investigated the correlation of the FFITh with pain-VAS and with the EQ-5D because they indicated severity and health status. The findings demonstrated strong correlations between the total score of FFI-Th and subscales of pain and disability with the pain-VAS, EQ-5D-5L, and EQ-VAS. However, the activity limitation subscale demonstrated a strong correlation with EQ-5D-5L, when low and moderate correlations were found with EQ-VAS and pain-VAS. A strong correlation between the FFI-Th and EQ-5D-5L showed a congruence of foot function and health status determined from five domains. These validity results were similar to those related studies that investigated variable dimensions. Moderate to high correlations were found with pain-VAS [17, 20], function-VAS [17], physical and mental health status $[17,20,45]$, activity scale [17] and 
health-related quality of life [15, 46]. A study of a Spanish version FFI reported a moderate correlation of the questionnaire with the EQ-5D and with the pain-VAS and weak correlation with the 12-item short-form health survey (SF-12) [47]. A German version of the FFI [17] had a strong correlation with pain, a moderate correlation with the physical SF and a weak correlation with the mental SF. Whereas the Chinese version of the FFI [18] had a strong correlation with physical aspects of the 36-item short-form health survey (SF-36), but a weak correlation with the mental SF-36.

Regarding feasibility, a report about the difficulty in the 18-item German version of the FFI found a mean difficulty of only 2.4 on a 10-point VAS with the average time required for completion of $8 \mathrm{~min}$ [17]. However, this study did not capture the time of completion or ask about the difficulty of interpreting the items. Nevertheless, all individuals completed the questionnaire without complaint.

\section{Limitation of the study}

The study was limited by a low degree of foot pain severity and clinical symptom characteristics of the participants as well as a small sample number. This may affect the generalizability for the use of this tool in other kinds of population. The psychometric properties including responsiveness or sensitivity to change need to be studied. In addition, future studies should compare the original FFI with the revised shortened version and test with a range of foot problem severities.

\section{Conclusion}

The FFI-Th was shown to be a reliable and valid tool and provided good internal consistency.

Thai clinicians and researchers may use this tool to assess the foot function in patients with plantar foot complaints.

\section{Abbreviations}

FFI: Foot function index; FFI-Th: Foot function index Thai version; EQ-5D5L: EuroQol five-dimensional questionnaire; SF-12: 12-item short-form health survey; SF-36: 36-item short-form health survey; pain-VAS: Visual analog pain scale

\section{Acknowledgements}

We thank our physical therapists from the Faculty of Physical Therapy, Mahidol University who assisted in the data collection process and all participants who assisted in the study.

\section{Authors' contributions \\ SB participated in research conceptualization, data collection, data analysis, manuscript drafting and revision; ST, WI, and SS participated in data collection; RV participated in research conceptualization; RS participated in manuscript revision. All authors read and approved the final manuscript.}

\section{Funding}

The Thailand Research Fund and Mahidol University funding for this study. Also, partial support received from Faculty of Physical Therapy, Mahidol
University. The funders had no role in study design, data collection and analysis, decision to publish, or preparation of the manuscript.

\section{Availability of data and materials}

The datasets used and/or analysed during the current study are available from the corresponding author on reasonable request.

\section{Ethics approval and consent to participate}

The study has complied with relevant national regulations and policies and has followed the tenets of the Declaration of Helsinki which approved by the Mahidol University-Central Institutional Review Board (MU-CIRB COA no. 2016/173.3012). All participants have informed for the details and signed on the informed consent before participating in the study.

\section{Consent for publication}

Not applicable.

\section{Competing interests}

The authors declare that they have no competing interests.

\section{Author details}

${ }^{1}$ Faculty of Physical Therapy, Mahidol University, 999 Phuttamonthon 4 Rd. Salaya, Phuttamonthon, Nakhon Pathom 73170, Thailand. ${ }^{2}$ Physical Therapy Center, Faculty of Physical Therapy, Mahidol University, Bangkok 10700,

Thailand. ${ }^{3}$ Discipline of Exercise and Sport Science, School of Health Sciences, Faculty of Medicine and Health Science, The University of Sydney, Sydney, NSW 2006, Australia.

Received: 22 November 2019 Accepted: 1 September 2020 Published online: 10 September 2020

\section{References}

1. Menz HB, Morris ME, Lord SR. Foot and ankle risk factors for falls in older people: a prospective study. J Gerontol A Biol Sci Med Sci. 2006;61(8):86670.

2. Menz HB. Biomechanics of the ageing foot and ankle: a mini-review. Gerontology. 2015;61(4):381-8. https://doi.org/10.1159/000368357.

3. Leveille SG, Jones RN, Kiely DK, Hausdorff JM, Shmerling RH, Guralnik JM, Kiel DP, Lipsitz LA, Bean JF. Chronic musculoskeletal pain and the occurrence of falls in an older population. JAMA. 2009;302(20):2214-21. https://doi.org/10.1001/jama.2009.1738.

4. Gill TK, Menz HB, Landorf KB, Arnold JB, Taylor AW, Hill CL. Predictors of foot pain in the community: the north West Adelaide health study. J Foot Ankle Res. 2016;9:23. https://doi.org/10.1186/s13047-016-0150-9.

5. Hill CL, Gill TK, Menz HB, Taylor AW. Prevalence and correlates of foot pain in a population-based study: the north West Adelaide health study. J Foot Ankle Res. 2008;1(1):2. https://doi.org/10.1186/1757-1146-1-2.

6. Butterworth PA, Landorf KB, Smith SE, Menz HB. The association between body mass index and musculoskeletal foot disorders: a systematic review. Obes Rev. 2012;13(7):630-42. https:/doi.org/10.1111/j.1467-789X.2012.00996.X.

7. Dufour AB, Losina E, Menz HB, LaValley MP, Hannan MT. Obesity, foot pain and foot disorders in older men and women. Obes Res Clin Pract. 2017: 11(4):445-53. https://doi.org/10.1016/j.orcp.2016.11.001.

8. Chaiwanichsiri $D$, Janchai $S$, Tantisiriwat N. Foot disorders and falls in older persons. Gerontology. 2009;55(3):296-302. https://doi.org/10.1159/ 000181149 .

9. Awale A, Dufour AB, Katz P, Menz HB, Hannan MT. Link between foot pain severity and prevalence of depressive symptoms. Arthritis Care Res (Hoboken). 2016:68(6):871-6. https://doi.org/10.1002/acr.22779.

10. Menz HB. Chronic foot pain in older people. Maturitas. 2016;91:110-4. https://doi.org/10.1016/.j.maturitas.2016.06.011.

11. Picavet HS, Schouten JS. Musculoskeletal pain in the Netherlands: prevalences, consequences and risk groups, the DMC(3)-study. Pain. 2003; 102(1-2):167-78.

12. Budiman-Mak E, Conrad KJ, Roach KE. The foot function index: a measure of foot pain and disability. J Clin Epidemiol. 1991;44(6):561-70.

13. Budiman-Mak E, Conrad KJ, Mazza J, Stuck RM. A review of the foot function index and the foot function index - revised. J Foot Ankle Res. 2013;6(1):5. https://doi.org/10.1186/1757-1146-6-5.

14. Saag KG, Saltzman CL, Brown CK, Budiman-Mak E. The foot function index for measuring rheumatoid arthritis pain: evaluating side-to-side reliability. 
Foot Ankle Int. 1996;17(8):506-10. https://doi.org/10.1177/ 107110079601700814

15. Powell M, Seid M, Szer IS. Efficacy of custom foot orthotics in improving pain and functional status in children with juvenile idiopathic arthritis: a randomized trial. J Rheumatol. 2005;32(5):943-50.

16. Vetrano M, Vulpiani MC, Erroi D, Vadala A, Ferretti A, Saraceni VM. Crosscultural adaptation and reliability of the Italian version of the foot function index (FFI-I) for patients with plantar fasciitis. J Sports Med Phys Fitness. 2014;54(5):636-43.

17. Naal FD, Impellizzeri FM, Huber M, Rippstein PF. Cross-cultural adaptation and validation of the foot function index for use in German-speaking patients with foot complaints. Foot Ankle Int. 2008;29(12):1222-8. https:// doi.org/10.3113/FAl.2008.1222.

18. Wu SH, Liang HW, Hou WH. Reliability and validity of the Taiwan Chinese version of the foot function index. J Formos Med Assoc. 2008;107(2):111-8. https://doi.org/10.1016/S0929-6646(08)60124-2.

19. Gonzalez-Sanchez M, Ruiz-Munoz M, Li GZ, Cuesta-Vargas Al. Chinese crosscultural adaptation and validation of the foot function index as tool to measure patients with foot and ankle functional limitations. Disabil Rehabil. 2018;40(17):2056-61. https://doi.org/10.1080/09638288.2017.1325944.

20. Martinelli N, Scotto GM, Sartorelli E, Bonifacini C, Bianchi A, Malerba F. Reliability, validity and responsiveness of the Italian version of the foot function index in patients with foot and ankle diseases. Qual Life Res. 2014; 23(1):277-84. https://doi.org/10.1007/s11136-013-0435-4.

21. Venditto T, Tognolo L, Rizzo RS, lannuccelli C, Di Sante L, Trevisan M, Maggiolini FR, Santilli V, loppolo F. 17-Italian foot function index with numerical rating scale: development, reliability, and validity of a modified version of the original foot function index. Foot (Edinb). 2015;25(1):12-8. https://doi.org/10.1016/j.foot.2014.09.004.

22. Paez-Moguer J, Budiman-Mak E, Cuesta-Vargas Al. Cross-cultural adaptation and validation of the foot function index to Spanish. Foot Ankle Surg. 2014; 20(1):34-9. https://doi.org/10.1016/j.fas.2013.09.005.

23. Yi LC, Staboli IM, Kamonseki DH, Budiman-Mak E, Arie EK. Translation and cross-cultural adaptation of FFI to Brazilian Portuguese version: FFI - Brazil. Rev Bras Reumatol. 2015. https://doi.org/10.1016/j.rbr.2014.11.004.

24. Jorgensen JE, Andreasen J, Rathleff MS. Translation and validation of the Danish foot function index (FFI-DK). Scand J Med Sci Sports. 2015;25(4): e408-13. https://doi.org/10.1111/sms.12331.

25. Anaforoglu Kulunkoglu B, Firat N, Yildiz NT, Alkan A. Reliability and validity of the Turkish version of the foot function index in patients with foot disorders. Turk J Med Sci. 2018;48(3):476-83. https://doi.org/10.3906/sag-1705-143.

26. Mousavian A, Mohammadi A, Seyed-Hosseinian SH, Shahpari O, Elahpour N, Orooji A, Ebrahimzadeh MH, Moradi A. Reliability and validity of the Persian version of the foot function index in patients with foot disorders. Arch Bone Jt Surg. 2019;7(3):291-6.

27. Srimakarat $P$, Jaroenarpornwatana A, Janchai S, Tantisiriwat N. Reliability and validity of foot function index Thai version [FFI-TH]. J Med Assoc Thail. 2018; 101(2):253-60

28. Ahlers SJ, van Gulik L, van der Veen AM, van Dongen HP, Bruins P, Belitser SV, de Boer A, Tibboel D, Knibbe CA. Comparison of different pain scoring systems in critically ill patients in a general ICU. Crit Care. 2008;12(1):R15. https://doi.org/10.1186/cc6789.

29. Li L, Liu X, Herr K. Postoperative pain intensity assessment: a comparison of four scales in Chinese adults. Pain Med. 2007:8(3):223-34. https://doi.org/10. 1111/j.1526-4637.2007.00296.x.

30. Skovlund $\mathrm{E}$, Flaten $\mathrm{O}$. Response measures in the acute treatment of migraine. Cephalalgia. 1995;15(6):519-22, discussion 450-511. https://doi.org/ 10.1046/j.1468-2982.1995.1506519.x.

31. Ferraz MB, Quaresma MR, Aquino LR, Atra E, Tugwell P, Goldsmith CH. Reliability of pain scales in the assessment of literate and illiterate patients with rheumatoid arthritis. J Rheumatol. 1990;17(8):1022-4.

32. Beaton DE, Bombardier C, Guillemin F, Ferraz MB. Guidelines for the process of cross-cultural adaptation of self-report measures. Spine (Phila Pa 1976). 2000;25(24):3186-91.

33. Herdman M, Gudex C, Lloyd A, Janssen M, Kind P, Parkin D, Bonsel G, Badia $X$. Development and preliminary testing of the new five-level version of EQ5D (EQ-5D-5L). Qual Life Res. 2011;20(10):1727-36. https://doi.org/10.1007/ s11136-011-9903-X

34. Pattanaphesaj J. Health-related quality of life measure (EQ-5D-5L): measurement property testing and its preference-based score in Thai population. PhD thesis. Bangkok: Mahidol University; 2014.
35. Huskisson EC. Measurement of pain. Lancet. 1974;2(7889):1127-31.

36. Jensen MP, Karoly P, Braver S. The measurement of clinical pain intensity: a comparison of six methods. Pain. 1986;27(1):117-26.

37. Scott J, Huskisson EC. Graphic representation of pain. Pain. 1976;2(2):175-84.

38. Bijur PE, Silver W, Gallagher EJ. Reliability of the visual analog scale for measurement of acute pain. Acad Emerg Med. 2001;8(12):1153-7.

39. Downie WW, Leatham PA, Rhind VM, Wright V, Branco JA, Anderson JA. Studies with pain rating scales. Ann Rheum Dis. 1978;37(4):378-81.

40. Koo TK, Li MY. A guideline of selecting and reporting Intraclass correlation coefficients for reliability research. J Chiropr Med. 2016;15(2):155-63. https:// doi.org/10.1016/j.jcm.2016.02.012.

41. Cohen J. Statistical power analysis for the behavioral sciences. 2nd ed. New Jersey: Lawrence Erlbaum Associates; 1988.

42. Agel J, Beskin JL, Brage M, Guyton GP, Kadel NJ, Saltzman CL, Sands AK, Sangeorzan BJ, SooHoo NF, Stroud CC, et al. Reliability of the foot function index: a report of the AOFAS outcomes committee. Foot Ankle Int. 2005; 26(11):962-7.

43. Kuyvenhoven MM, Gorter KJ, Zuithoff P, Budiman-Mak E, Conrad KJ, Post MW. The foot function index with verbal rating scales (FFI- $5 \mathrm{pt}$ ): a clinimetric evaluation and comparison with the original FFI. J Rheumatol. 2002;29(5): 1023-8.

44. Terwee CB, Bot SD, de Boer MR, van der Windt DA, Knol DL, Dekker J, Bouter LM, de Vet HC. Quality criteria were proposed for measurement properties of health status questionnaires. J Clin Epidemiol. 2007;60(1):3442. https://doi.org/10.1016/j.jclinepi.2006.03.012.

45. SooHoo NF, Samimi DB, Vyas RM, Botzler T. Evaluation of the validity of the foot function index in measuring outcomes in patients with foot and ankle disorders. Foot Ankle Int. 2006;27(1):38-42. https://doi.org/10.1177/ 107110070602700107

46. Williams AE, O'Neill TW, Mercer S, Toro B, Nester CJ. Foot pathology in patients with Paget's disease of bone. J Am Podiatr Med Assoc. 2006;96(3): 226-31.

47. Hurst NP, Kind P, Ruta D, Hunter M, Stubbings A. Measuring health-related quality of life in rheumatoid arthritis: validity, responsiveness and reliability of EuroQol (EQ-5D). Br J Rheumatol. 1997;36(5):551-9.

\section{Publisher's Note}

Springer Nature remains neutral with regard to jurisdictional claims in published maps and institutional affiliations.

Ready to submit your research? Choose BMC and benefit from:

- fast, convenient online submission

- thorough peer review by experienced researchers in your field

- rapid publication on acceptance

- support for research data, including large and complex data types

- gold Open Access which fosters wider collaboration and increased citations

- maximum visibility for your research: over $100 \mathrm{M}$ website views per year

At $\mathrm{BMC}$, research is always in progress.

Learn more biomedcentral.com/submissions 